\title{
Pattern of Congenital Heart Disease in Children Presenting at Paediatric Cardiology Unit in Chattagram Maa Shishu-O-General Hospital, Chittagong
}

\author{
Sukhendu Shekhar Sen ${ }^{1 *}$ \\ Tanuka Barua \\ Dipika Dey ${ }^{1}$ \\ Mahmood A. Chowdhury ${ }^{1}$ \\ Lutfan Nessa ${ }^{2}$
}

'Department of Paediatrics Chattagram Maa-O-Shishu Hospital Medical College Chittagong, Bangladesh

${ }^{2}$ Department of Paediatrics Abdul Malek Ukil Medical College Noakhali, Bangladesh.

\section{*Correspondence to:}

\section{Dr. Sukhendu Shekhar Sen}

Assistant Professor

Department of Paediatrics

Chattagram Maa-O-Shishu Hospital Medical College

Chittagong, Bangladesh.

Mobile : +88 01713207027

Email:sukhendusen@gmail.com

\begin{abstract}
Background: Congenital Heart Disease (CHD) is the most common congenital problem in children. Early detection and proper management of congenital heart disease is very important to reduce mortality and morbidity. The purpose of this study was to find out the disease pattern of CHD among children in present situation in a center outside Dhaka. Methods: This study was conducted over a period from March 2016 to June 2017 prospectively and all patients with CHD was diagnosed by Color Doppler Echocardiography aging from 1st day of life to 12 years were included in the study. Results: Acyanotic CHD was most common among CHD. Atrial Septal Defect (ASD) was the commonest acyanotic congenital heart disease 100 (35.7 \%) followed by Ventricular Septal Defect (VSD) 77 (27.5\%). Commonest cyanotic CHD was Tetralogy of Fallot (TOF) 9 (3.2\%). Only $25.36 \%$ CHD were diagnosed during neonatal period whereas $54.64 \%$ were diagnosed during the period of 29 days to completion of 12 months. Most of the patient $(63.21 \%)$ were male. Conclusion: ASD was the commonest acyanotic CHD whereas TOF was the commonest cyanotic CHD. About $80 \%$ cases were diagnosed before 1 year of age. With the advancement of diagnostic facility and neonatal care, early detection of CHD is possible and treatment can be started at an earlier age.
\end{abstract}

Key words: Congenital Heart Disease; Children; ASD; VSD; TOF.

\section{INTRODUCTION}

Congenital Heart Disease (CHD) is the most common among congenital problems. CHD is about $25 \%$ of all congenital malformations and is the most common type of heart disease among children ${ }^{1}$. Worldwide, CHD are relatively common with a prevalence ranging from $1.0-6.6$ per 1000 live births. The prevalence was 1.0 per 1000 in Egyptian children, 6.6 per 1000 in Americans, 5.0 per 1000 in Chinese ${ }^{2-4}$. It causes economic burden and psychological impact on the affected families.

It is very important to find out pattern of CHD among children for proper management. In the western countries pattern of CHD is well documented, but it has not been studied nationwide in Bangladesh. Rahman et al found $\operatorname{ASD}(39.9 \%)$ as commonest CHD followed by VSD (28.4\%) TOF (28.6\%) and PDA $(5.2 \%)^{5,6}$. Begum et al found ASD as the commonest CHD in neonate. Hussain et al found VSD (52.8\%) ASD (11.1\%) TOF (22.2\%) and PDA (8.3\%) as the common $\mathrm{CHD}^{7-9}$. Sharmin et al found VSD in $42.6 \%$, TOF $18.3 \%$ and ASD $14.8 \%{ }^{10}$. So different pattern of CHD is seen in Bangladesh in different study. There is little study about pattern of CHD outside Dhaka. 
Early detection, timely referral to proper center and adequate management is most important for long term outcome and better quality of life.But in Bangladesh lack of awareness and diagnostic facilities make the detection of CHD difficult. The purpose of this study was to find out pattern of CHD in children attending in Chattagram Maa-Shishu-O-General Hospital, Chittagong which is the largest pediatric care hospital in Chittagong providing service to the children coming from surrounding 7 districts having 650 beds along with a 4 bedded Pediatric Cardiology Unit.

\section{MATERIALS AND METHODS}

This was a hospital based, cross sectional study. The study included new cases referred to the Pediatric Cardiology Unit, Chattagram Maa-Shishu-O-General Hospital, Chittagong from March 2016 to June 2017. The cases were diagnosed by color doppler echocardiography. Patients with acquired heart diseases such as rheumatic heart diseases, cardiomyopathy were not included in this study. Consideration was given to number of cases with CHD, age at diagnosis, sex distribution and type of CHD.

\section{RESULTS}

Total 280 children were diagnosed as CHD during the study period. ASD 100 (35.7\%) was the most common acyanotic CHD in children followed by VSD 77 (27.5\%) and PDA (16.4 $\%)$. TOF was the common cyanotic CHD 9 (3.2\%).

Table 1: Pattern of CHD in children.

\begin{tabular}{|c|c|c|c|c|c|c|c|}
\hline \multirow{2}{*}{$\begin{array}{l}\text { Disease/ } \\
\text { Age }\end{array}$} & \multicolumn{2}{|c|}{ Day 1 to Day 28} & \multicolumn{2}{|c|}{ D29 to12 months } & \multicolumn{2}{|c|}{1 to 12 Years } & \multirow[b]{2}{*}{ Total } \\
\hline & Male & Female & Male & Female & Male & Female & \\
\hline ASD & 11 & 4 & 52 & 16 & 9 & 8 & $100(35.7 \%)$ \\
\hline VSD & 7 & 8 & 25 & 19 & 8 & 10 & $77(27.5 \%)$ \\
\hline PDA & 16 & 11 & 8 & 6 & 1 & 4 & $46(16.4 \%)$ \\
\hline Valvular HD & 1 & 0 & 7 & 2 & 4 & 5 & $19(6.8 \%)$ \\
\hline Dextrocardia & 0 & 0 & 0 & 1 & 0 & 0 & $1(0.4 \%)$ \\
\hline Ebstein Anomaly & 2 & 0 & 0 & 0 & 0 & 0 & $2(0.7 \%)$ \\
\hline Tetralogy of Fallot & 1 & 1 & 1 & 1 & 4 & 1 & $9(3.2 \%)$ \\
\hline TGA & 1 & 0 & 2 & 0 & 0 & 0 & $3(1.1 \%)$ \\
\hline AVSD & 4 & 0 & 0 & 2 & 0 & 0 & $6(2.1 \%)$ \\
\hline PA-VSD & 0 & 0 & 2 & 2 & 0 & 0 & $4(1.4 \%)$ \\
\hline Truncus Arteriosus & 0 & 0 & 1 & 0 & 0 & 0 & $1(0.4 \%)$ \\
\hline DORV & 0 & 0 & 2 & 0 & 0 & 0 & $2(0.7 \%)$ \\
\hline HPLHS & 2 & 1 & 0 & 0 & 0 & 0 & $3(1.1 \%)$ \\
\hline Single Ventricle & 1 & 0 & 2 & 1 & 0 & 0 & $4(1.4 \%)$ \\
\hline TAPVR & 0 & 0 & 3 & 0 & 0 & 0 & $3(1.1 \%)$ \\
\hline Total & 46 & 25 & 105 & 50 & 26 & 28 & 280 \\
\hline
\end{tabular}

Table 2 : Age and sex distribution of children with CHD.

$\begin{array}{lrrrr}\text { Sex/Age } & \text { D1-28 } & \text { D29 to 12 month } & 1 \text { to } 12 \text { years } & \text { Total } \\ \text { Male } & 46 & 105 & 26 & 177(63.21 \%) \\ \text { Female } & 25 & 50 & 28 & 103(36.79 \%) \\ \text { Total } & 71(25.36 \%) & 155(55.36 \%) & 54(19.28 \%) & 280(100 \%)\end{array}$

Most of the patients (54.64\%) were diagnosed during the age of day 29 - 12 months, whereas only $25.36 \%$ of patients were diagnosed during neonatal period.

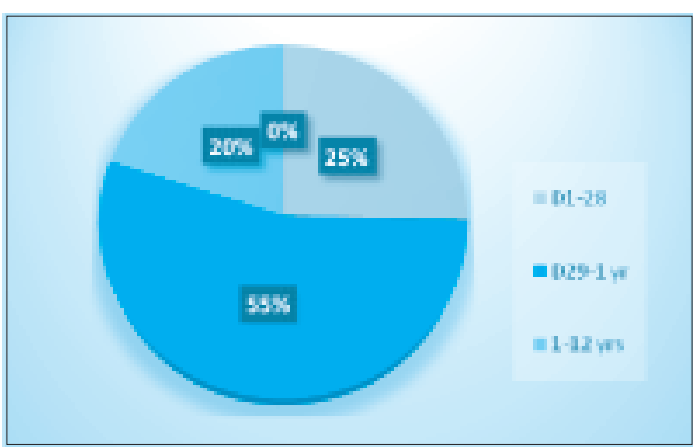

Figure 1: Age distribution of children with CHD.

$63.21 \%$ patients were male with male to female ratio $1.7: 1$.

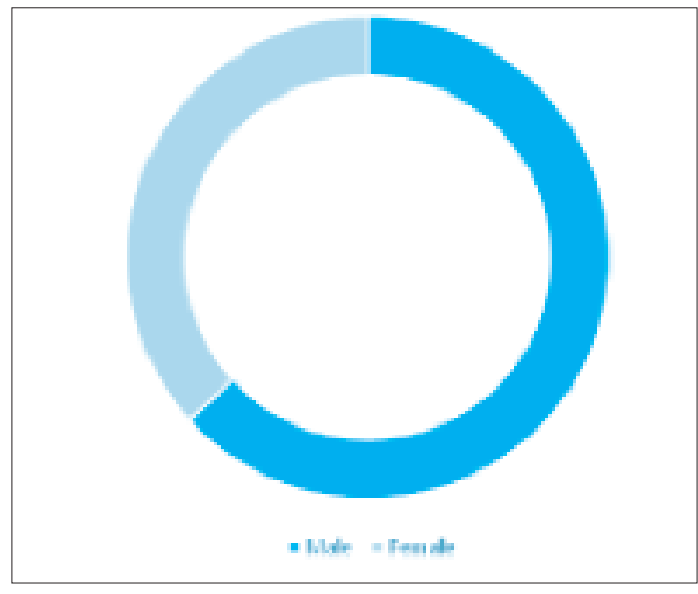

Figure 2 : Sex distribution of children with CHD

Only $11.1 \%$ patients were suffering from cyanotic CHD.

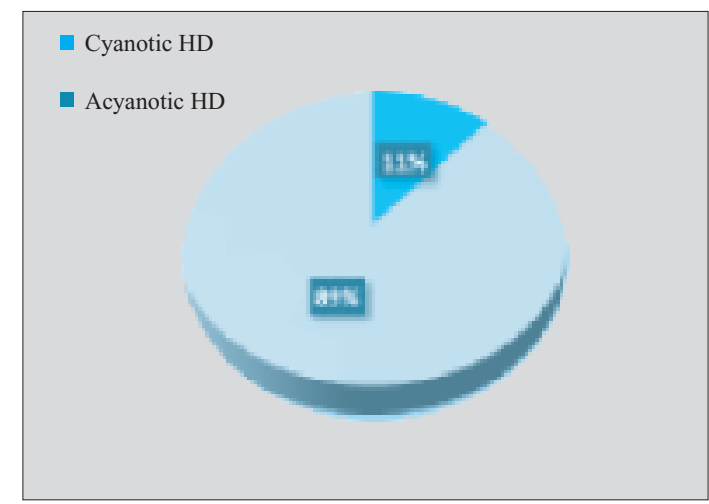

Figure 3 : Distribution of cyanotic and acyanotic CHD. 


\section{DISCUSSION}

Congenital heart disease is the most common congenital malformation. Many infants require corrective or palliative surgery and frequent hospitalization during 1st year of life. Early detection, timely referral to proper center and adequate management is most important for long term outcome and better quality of life.

Most of the studies regarding pattern of CHD were hospital based so estimation of magnitude of the CHD was not possible. Our study is also a hospital based study in Chittagong.

In our study, $63.21 \%$ patients were male with male to female ratio 1. 7: 1. Islam $\mathrm{MN}$ found male and female ratio was $1.2: 1^{11}$.

Hussain et al during early nineties found only $8.3 \%$ CHD at neonatal period ${ }^{9}$. Similar result was found by Rahim et al in Pakistan who detected only $8 \%$ CHD during neonatal period ${ }^{12}$. In our study about $25.34 \%$ of cases were diagnosed during neonatal period. Maximum number were diagnosed during the age of day 29 to 12 months (55\%). Hussain et al also found majority of CHD during infancy which support our study 9 .

In our study, commonest CHD is acyanotic CHD (88.9 \%). Similar result was found by Rahman et al, Begum et al Hussain, Sharmin et al, Rahim et al ${ }^{6-10,12}$.

In our study the commonest type of Congenital heart disease was atrial septal defect (ASD) (35.7\%). Rahman et al and Fatema et al found ASD as the commonest lesion ${ }^{6,8}$. Fatema et al found ASD as the commonest lesion in neonates ${ }^{8}$. In our study about $25 \%$ of our study population were neonate and $55 \%$ were infant, which may result in increased ASD number.
Hussain et al Sharmin et al and Rahim et al in their study found commonest CHD was VSD ${ }^{5,7,11}$. In our study, VSD was found in $27.5 \%$ of cases. Suryakant et al, Mishra found 25\% of cases as VSD in Latur district, India, which is consistent with our study ${ }^{13,14}$.

In this study commonest cyanotic heart disease were TOF (3.2\%).Rahman et al, Hussain et al, Sharmin et al, Suryakant et al, Mishra et al, Hussain et al found TOF as commonest cyanotic CHD but Begum et al found TOF and TGA in equal number in neonate $6,9,10,13-15,7$.

\section{CONCLUSION}

Majority of CHD in children upto 12 years of age are acyanotic. ASD was the commonest acyanotic CHD followed by VSD and PDA whereas TOF was the commonest cyanotic lesion. About $25 \%$ of children were diagnosed during neonatal period but maximum number were diagnosed during infancy $(55 \%)$. Majority of the patients were male $(63.21 \%)$. With the advancement of diagnostic facility and neonatal care, early detection of $\mathrm{CHD}$ is possible by $2 \mathrm{D}$ and color Doppler echocardiography, and may help to treat it at an earlier age and thus give the affected children and their parent's hope of a better future.

\section{DISCLOSURE}

All the authors declared no competing interest. 


\section{REFERENCES}

1. Schoen FJ. The Heart. In: Cortan RS, Kumar V, Robins SL, editors. Robins Pathologic Basis of Disease. $6^{\text {th }}$ ed. Philadelphia: W.B. Saunders Company, 1999;543-600.

2. Bassili A, Mokhtar SA, Dabous NI, Zaher SR, Mokhtar MM, Zaki A. Congenital heart disease among school children in Alexandria, Egypt: An overview on prevalence and relative frequencies. J Trop Pediatr. 2000; 46: 357-362.

3. Fixler DE, Pastor P, Chamberlin M, Sigman E, Eifler CW. Trends in congenital heart disease in Dallas County births. 1971-1984. Circulation. 1990; 81: 137-142.

4. Jiang LH, Duan CQ, Ma ZQ, Zhu LJ, Yin WJ, Zou HL et al. [Epidemiological investigation on congenital heart disease in several regions of Yunnan province]. Zhonghua Liu Xing Bing Xue Za Zhi. 2005; 26: 182-186.

5. Ruan Y, Liu N, Napolitano C \& Priori S G. Sign \& symptom of congenital heart diseases. Circ Arrhythm Electrophysiol. 2008; 1(4): $290-297$.

6. Rahman S, Ahmed MN, Rahmatullah KHI, Alam MS. The incidence of congenital heart diseases diagnosed by non-invasive technique : Ten years study in Bangladesh. D S (Child) H J. 1992; 8: 5-15.

7. Begum NNF, Ahmed QS. Pattern of heart disease among neonates and their outcome: One year experience in non-invasive cardiac laboratory of Combined Military Hospital, Dhaka. Bangladesh J Child Health. 2001; 25: 48-52.

8. Fatema NN. Incidence of CHD among hospital live birth in a tertiary hospital. Bang CV Journal. 2008; 1: 14-20.

9. Hussain M, Hossain M, Amin SK, Molla MR. Pattern of congenital heart disease in Dhaka Shishu Hospital. D S (Child) H J. 1992; 8: 35-46.

10. Sharmin LS, Haque MA, Bari MI, Ali MA. Pattern and clinical profile of congenital heart disease in a Teaching Hospital. TAJ. 2008; $21: 58-62$.

11. Islam MN, Hossain MA, Khaleque MA, Das MK, Khan MRH, Bari MS, Bhuiyan MKJ. Nepal Journal of Medical Sciences 2013; 02:91-95.

12. Rahim F, Younas M, Gandapur AJ, Talat A. Pattern of congenital heart disease in children at tertiary care centre in Peshawar. Pak J Med Sci. 2003; 19:19-22.

13. Surjakant $\mathrm{H}$. Nisale, Vidyadhar G. Maske. A study of prevalence and pattern of congenital heart disease and rheumatic heart disease among school children. Int J Adv Med. 2016 ;3(4):947-951.

14. Mishra M, Mittal M, Verma AM et al. Prevalence and pattern of congenital heart disease in school children of Eastern Uttar Pradesh. Indian Heart J.2009;61: 281-285.

15. Hussain M, Tahura S, Sayeed MA, Rahman MM, Rahman MM, Kar SK.Past and Present Pattern of Congenital Heart Disease at Dhaka Shishu Hospital: A Situation Analysis.BANGLADESH J CHILD HEALTH. 2010;34 (2): 51-55. 